EPIDEMIOLOGICAL REVIEW

\title{
Sentinel surveillance of sexually transmitted infections in South Africa: a review
}

\author{
L F Johnson, D J Coetzee, R E Dorrington
}

Sex Transm Infect 2005;81:287-293. doi: 10.1136/sti.2004.013904

See end of article for authors' affiliations

.....................

Correspondence to: Leigh Johnson, Centre for Actuarial Research, 10 University Avenue, University of Cape Town, Private Bag, Rondebosch 7701, South Africa; ljohnson@commerce.uct. ac.za

Accepted for publication 3 February 2005
Objectives: To review studies of sexually transmitted infection (STI) prevalence in South Africa between 1985 and 2003 in selected sentinel populations. To examine how STI prevalence varies between populations and to identify the limitations of the existing data.

Methods: Studies of the prevalence of syphilis, chancroid, granuloma inguinale, lymphogranuloma venereum, gonorrhoea, chlamydia, trichomoniasis, bacterial vaginosis, candidiasis, and herpes simplex virus type 2 (HSV-2) were considered. Results were included if they related to women attending antenatal clinics or family planning clinics, commercial sex workers, individuals in the general population (household surveys), patients with STIs, patients with genital ulcer disease (GUD), or men with urethritis.

Results: High STI prevalence rates have been measured, particularly in the case of HSV-2, trichomoniasis, bacterial vaginosis and candidiasis. The aetiological profile of GUD appears to be changing, with more GUD caused by HSV-2 and less caused by chancroid. The prevalence of gonorrhoea and syphilis is highest in "high risk" groups such as sex workers and attenders of STI clinics, but chlamydia and trichomoniasis prevalence levels are not significantly higher in these groups than in women attending antenatal clinics.

Conclusions: The prevalence of STls in South Africa is high, although there is extensive variability between regions. There is a need for STI prevalence data that are more nationally representative and that can be used to monitor prevalence trends more reliably.
S urveillance of the prevalence of sexually transmitted infections (STIs) is recognised increasingly as a key priority in public health. The sexual transmission of HIV occurs more readily in the presence of other STIs, ${ }^{1}$ and both mathematical models and empirical data suggest that these STIs account for a high proportion of incident HIV infections. ${ }^{2-4}$ STIs are also responsible for a high proportion of adverse pregnancy outcomes. ${ }^{5}$ The monitoring of STI prevalence is crucial for the evaluation of STI treatment programmes, and can also provide an indirect measure of change in sexual behaviour.

South Africa is one of the few African countries to have nationally representative data on the prevalence of HIV and (to a lesser extent) syphilis. ${ }^{67}$ For other STIs, there are no nationally representative microbiological studies, but there are many sentinel surveillance studies. The results of these studies are difficult to compare, because of differences in populations sampled and differences in diagnostic methods used. Almost all of the studies are conducted among users of public health facilities, and there are very few studies of STI prevalence in individuals of higher socioeconomic status.

The objective of this paper is to review the STI sentinel surveillance studies that have been conducted in South Africa between the beginning of 1985 and the end of 2003. These results are used to draw conclusions about the changing epidemiology of STIs in South Africa, and the limitations of the existing data are discussed.

\section{METHODS}

Sentinel surveillance studies were identified using a number of different sources. A computerised search of the Medline database was conducted on 4 February 2004. The search term was "South Africa and (herpes or syphilis or treponema pallidum or chancroid or haemophilus ducreyi or chlamydia or gonorrhoea or neisseria gonorrhoeae or trichomoniasis or trichomonas vaginalis or bacterial vaginosis or candidiasis or candida albicans or lymphogranuloma venereum or granuloma inguinale or donovanosis or calymmatobacterium granulomatis)." This search yielded a total of 916 hits. Further studies were identified from an earlier review of studies conducted between 1980 and $1995,{ }^{8}$ and by manually searching the Southern African Journal of Epidemiology and Infection. Grey literature was identified by searching the abstracts of recent AIDS conferences and by consulting local STI experts.

The focus of this study is restricted to sentinel populations that are frequently studied: women attending antenatal clinics and family planning clinics, commercial sex workers, men and women in the general population (household surveys), patients with STIs, patients with genital ulcer disease (GUD), and men with urethritis. Human papillomavirus has not been included in this review, as the sentinel populations in which this disease is monitored usually differ from those in which other STIs are monitored, and the epidemiology of the disease is complex. Human immunodeficiency virus (HIV) has also not been included, as the prevalence of this disease has already been studied extensively in more nationally representative studies. ${ }^{67}$ The focus of this review is further limited to microbiological prevalence data and does not include estimates of the prevalence of STI symptoms. Studies were excluded if they were conducted before 1985 or (in cases where the date of the study was not reported) published before 1985 .

\section{RESULTS}

After applying the exclusion criteria, a total of 47 independently conducted studies (that is, studies conducted in different periods or by different investigators) were

Abbreviations: GUD, genital ulcer disease; ELISA, enzyme linked immunosorbent assay; HSV, herpes simplex virus; RPR, rapid plasma reagin; STI, sexually transmitted infection 


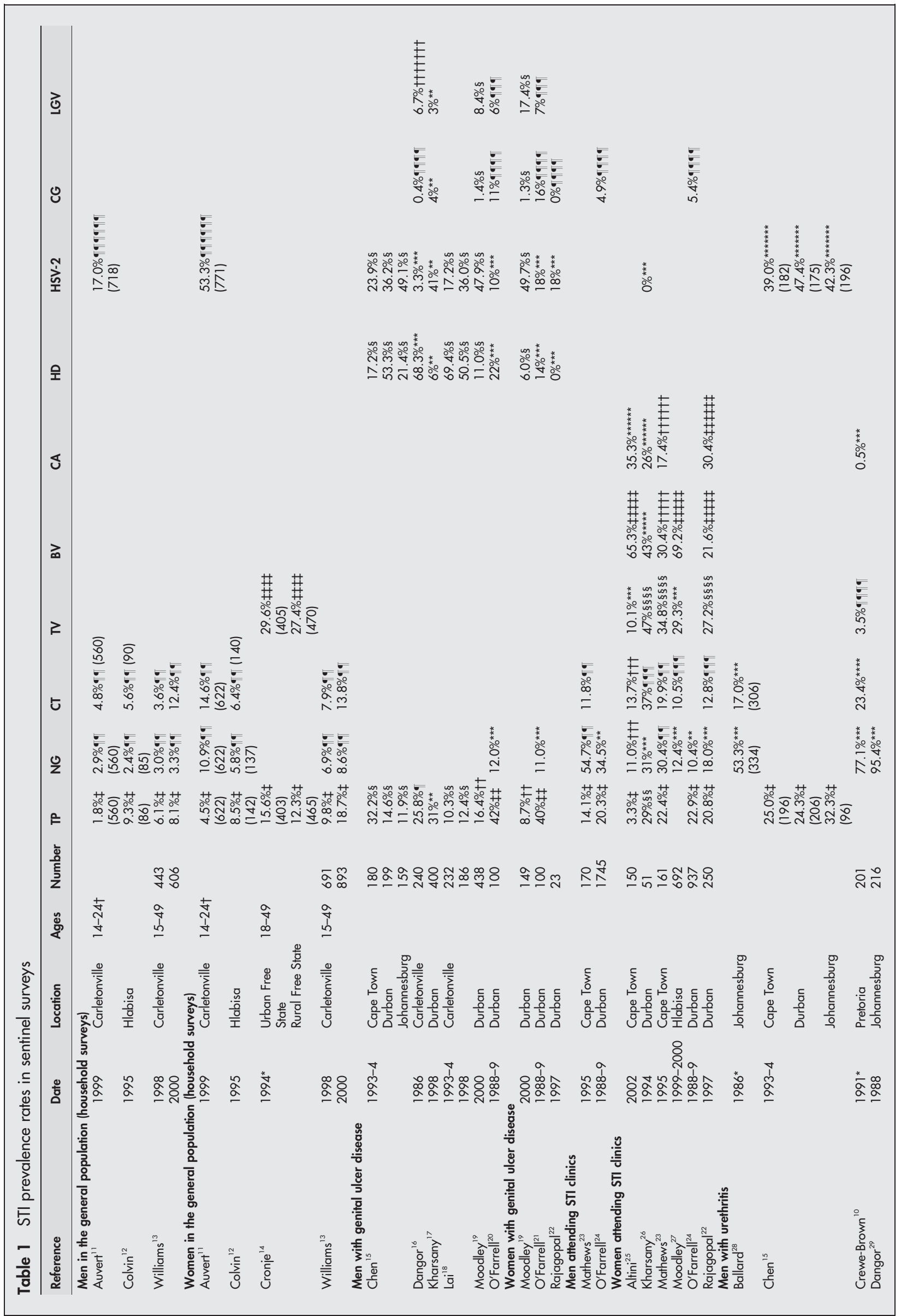




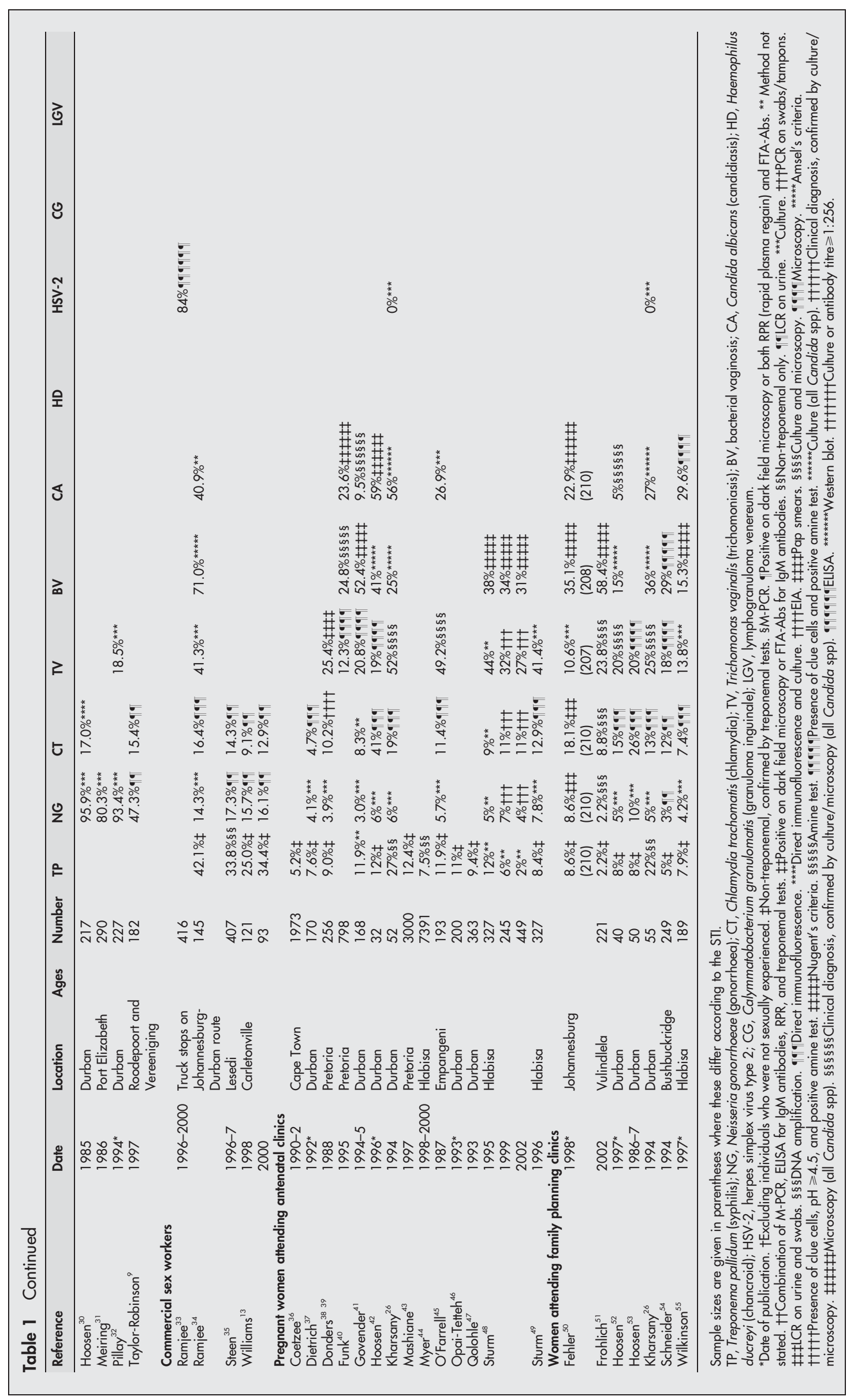


identified. Of these, 34 were conducted in urban areas, 11 were conducted in rural areas, 1 was conducted in both rural and urban areas, and one could not be classified. Of the 47 studies, 25 were conducted in KwaZulu-Natal, 14 were conducted in Gauteng, three were conducted in Western Cape, one was conducted in all three of these provinces, and four were conducted in other provinces. Only two studies were conducted among users of private health facilities. ${ }^{9}{ }^{10}$ The study characteristics and STI prevalence estimates for each sentinel population are shown in table 1. In general, there is little consistency in diagnostic methods used. In the case of men and women with GUD, results represent the proportion of ulcers in which each STI was detected rather than the prevalence of infection, though two studies of GUD patients also measured the prevalence of gonorrhoea.

The seroprevalence of syphilis (Treponema pallidum) is typically around $10 \%$ in women attending antenatal and family planning clinics. Prevalence rates are significantly higher in "high risk" groups such as sex workers and men with urethritis $(24 \%-42 \%)$. Although there is little consistency between studies in terms of techniques used to detect syphilis in genital ulcer specimens, studies involving the more accurate M-PCR have usually estimated that between $10 \%$ and a third of GUD cases are attributable to syphilis.

Chancroid (Haemophilus ducreyi) has been studied exclusively in individuals with GUD. Historically, the disease has accounted for over $50 \%$ of GUD in males, and a substantially lower proportion of GUD in females. There appears to have been a significant decline in the proportion of ulcers attributable to chancroid in recent years. All studies of the disease have been conducted in urban centres in Gauteng, Durban, and Cape Town, with proportions of GUD cases attributable to chancroid usually being higher in urban Gauteng than in Durban and Cape Town.

In contrast with chancroid, herpes simplex virus type 2 (HSV-2) appears to be responsible for an increasingly high proportion of male GUD. Data on the seroprevalence of HSV2 are scarce. The only estimate of prevalence in "low risk" groups is from a household survey of 14-24 year old individuals in a mining town, ${ }^{11}$ which is likely to underestimate the seroprevalence of HSV-2 at older ages. In high risk groups, seroprevalence rates range from almost $50 \%$ in men with urethritis to over $80 \%$ in commercial sex workers.

The two other causes of GUD that are commonly studied, granuloma inguinale (Calymmatobacterium granulomatis) and lymphogranuloma venereum (Chlamydia trachomatis), are both relatively rare. With the exception of one study which found granuloma inguinale to account for more than $10 \%$ of GUD cases, ${ }^{20}{ }^{21}$ most studies estimate the proportion of GUD attributable to granuloma inguinale to be close to $1 \%$. Lymphogranuloma venereum usually accounts for $3-10 \%$ of GUD cases, with occasional exceptions. ${ }^{19}$

Gonorrhoea (Neisseria gonorrhoeae) accounts for the vast majority of urethritis cases in men, and men attending STI clinics also have extremely high prevalence rates. The prevalence of the disease in women attending family planning and antenatal clinics is usually around 5\%. As with syphilis, the prevalence of the disease in women is significantly higher in high risk groups such as sex workers and women attending STI clinics (10-31\%).

Chlamydia (Chlamydia trachomatis) is more prevalent than gonorrhoea in low risk groups, but its prevalence is lower than that of gonorrhoea in individuals with STI symptoms. Unlike gonorrhoea and syphilis, chlamydia does not appear to be substantially less prevalent in antenatal clinics and family planning clinics than in high risk groups such as sex workers and STI clinic attenders.

Few studies of trichomoniasis (Trichomonas vaginalis) have been conducted in men. It would appear that this disease accounts for less than $20 \%$ of male urethritis cases, a lower proportion than that for gonorrhoea and chlamydia. In women, however, the disease is highly prevalent, with prevalence rates typically in excess of $20 \%$. Like chlamydia, its prevalence appears not to differ substantially between women in antenatal and family planning clinics and women in STI clinics.

Bacterial vaginosis and candidiasis (Candida albicans) are also conditions that are highly prevalent in women, although they are not traditionally regarded as STIs. In both cases, there is much inconsistency in the diagnostic algorithms used, and the data also show little consistency. It is clear, however, that the prevalence of bacterial vaginosis is extremely high, with the highest prevalence rates being observed in STI clinic attenders and sex workers. The prevalence of candidiasis is usually between $20 \%$ and $40 \%$, except in studies in which definitions are based on clinical diagnosis.

Three of the studies have involved periodic assessments in the same sentinel population. A study of pregnant women in Hlabisa found that the prevalence of syphilis and trichomoniasis had declined significantly between 1995 and 2002, but changes in diagnostics used over the period obscure the change in the prevalence of other STIs. ${ }^{48}$ In contrast, a study in Carletonville found increases in the prevalence of syphilis, gonorrhoea, and chlamydia between 1998 and 2000, in both men and women in the general population and in sex workers. ${ }^{13}$ The third survey, also conducted in Carletonville, found significantly increased detection of HSV-2 in male genital ulcers between 1993-4 and 1998, while the frequency of chancroid detection reduced significantly and the frequency of syphilis detection remained roughly unchanged..$^{18}$

\section{DISCUSSION}

This study updates the earlier review of Pham-Kanter et al, ${ }^{8}$ and demonstrates the continuing STI burden in South Africa. STI prevalence rates in South Africa are high, even when compared with other African countries. The prevalence of gonorrhoea, chlamydia, and trichomoniasis in South African household surveys exceeds that estimated in recent household surveys conducted in various African cities ${ }^{56} 57$ and in communities in Uganda and Tanzania. ${ }^{58}$ The prevalence of these STIs in South African sex workers is also generally comparable to or higher than that observed recently in sex workers from other African countries. ${ }^{59}$ This high STI prevalence rate may be a reflection of the high levels of migration in South Africa, the legacy of the migrant labour system that existed during the apartheid era. ${ }^{60}$ It may also be because the HIV/AIDS epidemic in South Africa is less mature than the epidemic in other African countries. Model simulations suggest that bacterial STIs decline in prevalence over the course of an HIV/AIDS epidemic, ${ }^{61}$ and the relatively late start to the South African HIV/AIDS epidemic would therefore suggest a higher prevalence of curable STIs than in other African countries.

Studies from other African countries suggest that there have been significant declines in the prevalence of curable STIs in recent years. ${ }^{62-66}$ The data reviewed in this paper are of limited use in determining whether or not similar declines are occurring in South Africa. Although it is possible to adjust for the differences in diagnostic techniques used in different sentinel surveys, ${ }^{58}$ there remains substantial heterogeneity between individual surveys in terms of populations sampled, and this reduces the reliability of statistical tests for trend. Only three studies have involved periodic assessments of STI prevalence in the same sentinel population, and these do not show consistent trends.

These limitations aside, it would appear that HSV-2 is accounting for an increasingly high proportion of GUD cases 
in men, while chancroid is accounting for fewer GUD cases. The decline in the detection of chancroid in recent years may be related to the introduction of syndromic management protocols in South Africa since 1994, or to the rising levels of condom use observed in South Africa recently. ${ }^{7}$ However, it is not clear to what extent the increased isolation of HSV-2 in genital ulcers is the result of declines in the prevalence of other STIs that cause GUD, and to what extent it is the result of changes in HSV-2 seroprevalence. HIV prevalence might be associated with rising HSV-2 seroprevalence, since HIV COinfection increases HSV-2 viral shedding and hence HSV-2 transmissibility. ${ }^{67-69}$ However, there are no reliable local seroprevalence data to demonstrate temporal changes in HSV-2 seroprevalence. Although the HSV-2 seroprevalence in men with GUD appears to be lower in $1993-4^{15}$ than the seroprevalence rates of close to $100 \%$ recorded in male GUD patients in the early $1980 \mathrm{~s}^{70}{ }^{71}$ the latter are probably exaggerated owing to the poor performance of the early HSV-2 enzyme linked immunosorbent assay (ELISA), which showed extensive cross reactivity with HSV-1. ${ }^{72}$ There is a need for greater monitoring of HSV-2 seroprevalence in South Africa, particularly as this infection has been found to be highly correlated with HIV infection. ${ }^{11}$

Within South Africa, STI prevalence levels are highly variable. Chancroid, for example, seems to account for a higher proportion of GUD cases in Gauteng than in Durban and Cape Town. This may be the result of the association between chancroid and sex work, ${ }^{8}$ as levels of migrant labour and corresponding frequencies of commercial sex are particularly high in Gauteng.

Although the risk of syphilis and gonorrhoea infection is substantially higher in "high risk" groups than in women attending antenatal clinics, this is not the case for trichomoniasis and chlamydia. Other African studies have also failed to detect a significant association between trichomoniasis infection and sexual risk behaviours, ${ }^{57} 7374$ which suggests that other factors may play a more important part in the epidemiology of this disease. Acquired immunity to chlamydia may explain the lack of association between chlamydia and sentinel facility type. ${ }^{75}$

The geographical distribution of sentinel surveillance studies is generally not proportional to that of the South African population. Of the 47 independently conducted studies, 43 were conducted in KwaZulu-Natal, Gauteng, or Western Cape, though these provinces accounted for only $49 \%$ of the South African population in the 1996 census. $^{76}$ Thirty four of the studies were conducted exclusively in urban areas, though only $54 \%$ of the 1996 population lived in urban settlements. ${ }^{76}$ Most of the rural studies were conducted in Hlabisa (now Umkanyakude) in KwaZulu-Natal. In addition, many of the studies were conducted in Carletonville, the largest gold mining complex in the world. ${ }^{77}$ Exceptionally high HIV prevalence rates have been observed in this centre, ${ }^{77}$ and STI prevalence rates observed in Carletonville are not likely to be representative of those in the rest of the country. Several other problems result from the above sources of geographical bias. Granuloma inguinale, for example, occurs mainly in tropical and subtropical regions. ${ }^{78}$ Almost all of the South African studies of this disease have been conducted in Durban, and it is unlikely that these would be representative of other less tropical parts of the country.

Given the limitations associated with the sentinel surveillance data reviewed here, it is clear that there is a need for studies that are more nationally representative. There is also a need for more cross sectional studies conducted periodically in the same population, using the same diagnostic techniques, which can be used to monitor trends in STI prevalence more reliably. In addition, it is necessary to develop strategies
Key messages

- The prevalence of STls in South Africa is high, although STI prevalence varies substantially between sentinel populations

- Lack of consistency between sentinel surveys predudes a rigorous analysis of trends in STI prevalence, although there appears to be a change in the aetiological profile of genital ulcer disease

- There is a need for more nationally representative STI prevalence studies in South Africa and more periodic cross sectional studies that can be used to monitor prevalence trends and the success of STI treatment initiatives

for monitoring STIs treated in the private health sector. Only two of the studies reviewed here were conducted among patients of private practitioners, although almost half of STI cases are believed to be treated by private practitioners. ${ }^{79}$

Currently, the South African Department of Health conducts annual surveys of HIV and syphilis prevalence levels in pregnant women attending public antenatal clinics, and these surveys suggest significant declines in syphilis prevalence since 1997. ${ }^{6}$ The Department of Health also collects data on numbers of STI cases and male urethritis cases treated at public STI clinics, which do not show any significant trend. ${ }^{80}$ Data on the prevalence of other STIs and STI symptoms are lacking, but improved microbiological surveillance and drug resistance monitoring for different STI syndromes are currently being introduced ${ }^{80}$ The microbiological surveillance will be conducted in selected sites on a periodic basis, and its initial focus will be on ciprofloxacin resistance in gonococcal isolates. A clinical sentinel surveillance system is also being introduced at selected sites to collect more detailed data on the age, sex and presenting syndromes of patients attending public health facilities. ${ }^{80}$ While the new microbiological data will be useful, data collected only from STI clinics will be of limited use in monitoring trends in STI prevalence in the general population. It is therefore recommended that the new microbiological surveillance system incorporate other facilities such as antenatal and family planning clinics.

\section{ACKNOWLEDGEMENTS}

We would like to thank Lydia Altini, Francesca Little, and the anonymous reviewers for their helpful comments.

\section{CONTRIBUTORS}

This study was conceptualised by $\mathrm{LJ}$; it is part of a larger project conducted by LJ and supervised by RD; DC assisted in identifying unpublished literature; the manuscript was prepared by LJ, with contributions from DC and RD.

\section{Authors' affiliations}

LF Johnson, R E Dorrington, Centre for Actuarial Research, University of Cape Town, South Africa

D J Coetzee, School of Public Health and Family Medicine, University of Cape Town, South Africa

Competing interests: none.

\section{REFERENCES}

1 Røttingen J, Cameron DW, Garnett GP. A systematic review of the epidemiological interactions between classic sexually transmitted diseases and HIV: how much is really known? Sex Transm Dis 2001;28:579-97.

2 Robinson NJ, Mulder DW, Auvert B, et al. Proportion of HIV infections attributable to sexually transmitted diseases in a rural Ugandan population: simulation model estimates. Int J Epidemiol 1997;26:180-9. 
3 Orroth KK, Gavyole A, Todd J, et al. Syndromic treatment of sexually transmitted diseases reduces the proportion of incident HIV infections attributable to these diseases in rural Tanzania. AIDS 2000;14:1429-37.

4 Gray RH, Wawer MJ, Sewankambo NK, et al. Relative risks and population attributable fraction of incident HIV associated with symptoms of sexually transmitted diseases and treatable symptomatic sexually transmitted diseases in Rakai District, Uganda. AIDS 1999;13:2113-23.

5 De Schryver A, Meheus A. Epidemiology of sexually transmitted diseases: the global picture. Bull World Health Organ 1990;68:639-54.

6 Department of Health. National HIV and syphilis antenatal sero-prevalence survey in South Africa 2002. Cape Town: Department of Health, 2003.

7 Human Sciences Research Council. South African national HIV prevalence, behavioural risks and mass media household survey 2002. Cape Town: Human Sciences Research Council, 2002.

8 Pham-Kanter GBT, Steinberg MH, Ballard RC. Sexually transmitted diseases in South Africa. Genitourin Med 1996;72:160-71.

9 Taylor-Robinson D, Jensen JS, Fehler G, et al. Observations on the microbiology of urethritis in black South African men. Int J STD AIDS 2002; 13:323-5.

10 Crewe-Brown HH, Adam A, Ebrahim O, et al. The aetiology of acute urethritis in a southern African general practice. S Afr J Epidemiol Infect 1991;6:31-3.

11 Auvert B, Ballard R, Campbell C, et al. HIV infection in a South African mining town is associated with herpes simplex virus-2 seropositivity and sexual behaviour. AIDS 2001; 15:885-98.

12 Colvin M, Abdool Karim SS, Connolly C, et al. HIV infection and asymptomatic sexually transmitted infections in a rural South African community. Int J STD AIDS 1998;9:548-50.

13 Williams BG, Taljaard D, Campbell CM, et al. Changing patterns of knowledge, reported behaviour and sexually transmitted infections in a South African gold mining community. AIDS 2003;17:2099-107.

14 Cronje HS, Joubert G, Muir A, et al. Prevalence of vaginitis, syphilis and HIV infection in women in the Orange Free State. S Afr Med J 1994;84:602-5.

15 Chen CY, Ballard RC, Beck-Sague CM, et al. Human immunodeficiency virus infection and genital ulcer disease in South Africa: the herpetic connection. Sex Transm Dis 2000;27:21-9.

16 Dangor Y, Fehler G, Exposto F, et al. Causes and treatment of sexually acquired genital ulceration in southern Africa. S Afr Med J 1989;76:339-41.

17 Kharsany A, Mahabeer Y, Conolly C, et al. Changing aetiology of genital ulcer disease (GUD) in STD clinic attenders with a rising HIV prevalence. XIII International AIDS Conference; 9-14 July 2000; Durban, South Africa.

18 Lai W, Chen CY, Morse SA, et al. Increasing relative prevalence of HSV-2 infection among men with genital ulcers from a mining community in South Africa. Sex Transm Infect 2003:79:202-7.

19 Moodley P, Sturm PDJ, Vanmali T, et al. Association between HIV-1 infection, the etiology of genital ulcer disease, and response to syndromic management. Sex Transm Dis 2003;30:241-5.

20 O'Farrell N, Hoosen AA, Coetzee KD, et al. Genital ulcer disease in men in Durban, South Africa. Genitourin Med 1991;67:327-30.

21 O'Farrell N, Hoosen AA, Coetzee KD, et al. Genital ulcer disease in women in Durban, South Africa. Genitourin Med 1991;67:322-6.

22 Rajagopal M, Hoosen AA, Moodley J, et al. Analysis of genital tract infections at a dedicated sexually transmitted diseases clinic. S Afr J Epidemiol Infect $1999 ; 14: 77-82$.

23 Mathews C, van Rensburg A, Coetzee N. The sensitivity of a syndromic management approach in detecting sexually transmitted diseases in patients at a public health clinic in Cape Town. S Afr Med J 1998;88:1337-40.

24 O'Farrell N, Windsor I, Becker P. HIV-1 infection among heterosexual attenders at a sexually transmitted diseases clinic in Durban. S Afr Med J 1991;80:17-20

25 Altini $\mathrm{L}$, Jones $\mathrm{H}$, van de Wijgert J, et al. The validity, acceptability and feasibility of self-sampling for reproductive tract infections in South African women. ISSTDR Conference; 27-30 July 2003; Ottawa, Canada.

26 Kharsany ABM, Hoosen AA, Moodley J. Bacterial vaginosis and lower genital tract infections in women attending out-patient clinics at a tertiary institution serving a developing community. J Obstet Gynaecol 1997;17:171-5.

27 Moodley P, Wilkinson D, Connolly C, et al. Influence of HIV-1 coinfection on effective management of abnormal vaginal discharge. Sex Transm Dis 2003;30: 1-5

28 Ballard RC, Fehler HG, Bilgeri YR, et al. A clinical and microbiological evaluation of the treatment of urethritis with minocycline. S Afr J Epidemiol Infect 1986;1:19-24.

29 Dangor Y, Naidoo S, Ballard RC. The changing patterns of antimicrobial susceptibilities of Neisseria gonorrhoeae isolated in Johannesburg. S Afr J Epidemiol Infect 1991;6:34-6.

30 Hoosen AA, van den Ende J, Kharsany ABM. The aetiology of acute urethritis in black males in Durban, South Africa and penicillin susceptibility of Neisseria gonorrhoea isolates. S Afr J Epidemiol Infect 1987;2:4-6.

31 Meiring JA, Kemp E, Jennings DL, et al. High-level penicillin-resistant gonococcal infections in Port Elizabeth. S Afr Med J 1989;75:118-19.

32 Pillay DG, Hoosen AA, Vezi B, et al. Diagnosis of Trichomoniasis vaginalis in male urethritis. Trop Geogr Med 1994;46:44-5.

33 Ramjee G, Gouws E, Van Dyke E, et al. Herpes simplex virus type II infection is a risk factor for HIV seroconversion. South African Medical Research Council, Policy brief no 3, 2002.

34 Ramiee G, Abdool Karim SS, Sturm AW. Sexually transmitted infections among sex workers in KwaZulu-Natal, South Africa. Sex Transm Dis 1998:25:346-9.

35 Steen R, Vuylsteke B, DeCoito T, et al. Evidence of declining STD prevalence in a South African mining community following a core-group intervention. Sex Transm Dis 2000;27:1-8.
36 Coetzee N. Syphilis in women attending antenatal clinics in the Western Cape: a pilot investigation into the use of a laboratory based surveillance scheme. University of Cape Town Department of Community Health, 1994

37 Dietrich M, Hoosen AA, Moodley J, et al. Urogenital tract infections in pregnancy at King Edward VIII Hospital, Durban, South Africa. Genitourin Med 1992;68:39-41

38 Donders GGG, Desmyster J, De Wet DH, et al. The association of gonorrhoea and syphilis with premature birth and low birthweight. Genitourin Med 1993;69:98-101.

39 Donders GGG, De Wet HG, Hooft P, et al. Lactobacilli in papanicolaou smears, genital infections, and pregnancy. Am J Perinatol 1993;10:358-61.

40 Funk M, Pistorius LR, Pattison RC. Antenatal screening for bacterial vaginosis using the amine test. S Afr J Epidemiol Infect 1996;11:74-6.

41 Govender L, Hoosen AA, Moodley J, et al. Bacterial vaginosis and associated infections in pregnancy. Int J Gynecol Obstet 1996:55:23-8.

42 Hoosen A, Nteta C, Moodley J, et al. Diagnosis of bacterial vaginosis and its effect on pregnancy outcome: a preliminary study. S Afr J Epidemiol Infect 1996;11:104-6.

43 Mashiane Y, Chephe JH, Hoosen AA. Syphilis in pregnancy at Ga-Rankuwa Hospital: high prevalence and the need for intervention. S Afr J Epidemiol Infect 1999;14:13-15

44 Myer L, Wilkinson D, Lombard C, et al. Impact of on-site testing for maternal syphilis on treatment delays, treatment rates, and perinatal mortality in rural South Africa: a randomised control trial. Sex Transm Infect 2003:79:208-13.

45 O'Farrell N, Hoosen AA, Kharsany ABM, et al. Sexually transmitted pathogens in pregnant women in a rural South African community. Genitourin Med 1989;65:276-80.

46 Opai-Tetteh ET, Hoosen AA, Moodley J. Re-screening for syphilis at the time of delivery in areas of high prevalence. S Afr Med J 1993;83:725-6.

47 Qolohle DC, Hoosen AA, Moodley J, et al. Serological screening for sexually transmitted infections in pregnancy: is there any value in re-screening for HIV and syphilis at the time of delivery? Genitourin Med 1995;71:65-7.

48 Sturm A, Moodley P, Sturm P, et al. Trends in the prevalence of sexually transmitted infections and HIV in pregnant women in KwaZulu/Natal from 1995 to 2002. South African AIDS Conference; 3-6 August 2003; Durban, South Africa.

49 Sturm AW, Wilkinson D, Ndovela N, et al. Pregnant women as a reservoir of undetected sexually transmitted diseases in rural South Africa: implications for disease control. Am J Public Health 1998;88:1243-5.

50 Fehler HG, Lyall $M$, Htun $Y$, et al. Genital tract infections among women attending an urban family planning clinic. S Afr J Epidemiol Infect 1998;13:79-82.

51 Frohlich J, Abdool Karim Q, Abdool Karim S. Missed opportunities for treating sexually transmitted infections at a rural primary health care setting in South Africa. South African AIDS Conference; 3-6 August 2003; Durban, South Africa.

52 Hoosen AA, Moodley J, Maitin P, et al. Bacterial vaginosis in symptomatic women attending a gynaecology outpatient clinic. S Afr J Epidemiol Infect 1997; 12:119-21.

53 Hoosen AA, Quinlan DJ, Moodley J, et al. Sexually transmitted pathogens in acute pelvic inflammatory disease. S Afr Med J 1989;76:251-4.

54 Schneider H, Coetzee DJ, Fehler HG, et al. Screening for sexually transmitted diseases in rural South African women. Sex Transm Infect 1998;74(Suppl 1):S147-52.

55 Wilkinson D, Ndovela N, Harrison A, et al. Family planning services in developing countries: an opportunity to treat asymptomatic and unrecognized genital tract infections? Genitourin Med 1997;73:558-60.

56 Buvé A, Weiss HA, Laga $M$, et al. The epidemiology of gonorrhoea chlamydial infection and syphilis in four African cities. AIDS 2001;15(Suppl 4):S79-S88.

57 Buvé A, Weiss HA, Laga $M$, et al. The epidemiology of trichomoniasis in four African cities. AIDS 2001;15(Suppl 4):S89-96.

58 Orroth KK, Korenromp EL, White RG, et al. Comparison of STD prevalences in the Mwanza, Rakai, and Masaka trial populations: the role of selection bias and diagnostic errors. Sex Transm Infect 2003;79:98-105.

59 Morison L, Weiss HA, Buvé A, et al. Commercial sex and the spread of HIV in four cities in sub-Saharan Africa. AIDS 2001;15(Suppl 4):S61-9.

60 Jochelson K, Mothibeli M, Leger JP. Human immunodeficiency virus and migrant labor in South Africa. Int J Health Serv 1991;21:157-73.

61 Boily M, Bastos FI, Desai K, et al. Changes in the transmission dynamics of the HIV epidemic after the wide-scale use of antiretroviral therapy could explain increases in sexually transmitted infections. Sex Transm Dis 2004:31:100-13.

62 Moses S, Ngugi E, Costigan A, et al. Declining sexually transmitted disease and HIV prevalences among antenatal and family planning clinic attenders in Nairobi, Kenya, from 1992-1999. XIII International AIDS Conference; 9-14 July 2000; Durban, South Africa.

63 Taha TE, Dallabetta GA, Hoover DR, et al. Trends in HIV-1 and sexually transmitted diseases among pregnant and postpartum women in urban Malawi. AIDS 1998;12:197-203.

64 O'Farrell N. Increasing prevalence of genital herpes in developing countries: implications for heterosexual HIV transmission and STI control programmes. Sex Transm Infect 1999;75:377-84.

65 National AIDS Coordinating Agency. Second generation HIV/AIDS surveillance, 2002. Botswana: National AIDS Coordinating Agency, 2002.

66 Nagot N, Meda N, Ouangré A, et al. Review of STI and HIV epidemiological data from 1990 to 2001 in urban Burkina Faso: implications for STI and HIV control. Sex Transm Infect 2004;80:124-9. 
67 Schacker T, Zeh J, Hu H, et al. Frequency of symptomatic and asymptomatic herpes simplex virus type 2 reactivations among human immunodeficiency virus-infected men. J Infect Dis 1998;178:1616-22.

68 Augenbraun M, Feldman J, Chirgwin K, et al. Increased genital shedding of herpes simplex virus type 2 in HIV-seropositve women. Ann Intern Med 1995; 123:845-7.

69 Mbopi-Kéou F, Grésenguet G, Mayaud P, et al. Interactions between herpes simplex virus type 2 and human immunodeficiency virus type 1 infection in African women: opportunities for intervention. J Infect Dis 2000;182:1090-6.

70 Coovadia YM, Kharsany A, Hoosen A. The microbial aetiology of genital ulcers in black men in Durban, South Africa. Genitourin Med 1985;61:266-9.

71 Crewe-Brown HH, Krige FK, Davel GH, et al. Genital ulceration in males at Ga-Rankuwa Hospital, Pretoria. S Afr Med J 1982;62:861-3.

72 Ashley RL. Sorting out the new HSV type specific antibody tests. Sex Transm Infect $2001 ; 77: 232-7$.

73 Watson-Jones D, Mugeye K, Mayaud P, et al. High prevalence of trichomoniasis in rural men in Mwanza, Tanzania: results from a population based study. Sex Transm Infect 2000;76:355-62.
74 Connolly CA, Ramiee G, Sturm AW, et al. Incidence of sexually transmitted infections among HIV-positive sex workers in KwaZulu-Natal, South Africa. Sex Transm Dis 2002;29:721-4.

75 Brunham RC, Kimani J, Bwayo J, et al. The epidemiology of Chlamydia trachomatis within a sexually transmitted diseases core group. J Infect Dis 1996;173:950-6.

76 Statistics South Africa. Census in brief, 1999.

77 Williams BG, Gouws E, Colvin M, et al. Patterns of infection: using age prevalence data to understand the epidemic of HIV in South Africa. S Afr J Sci 2000;96:305-12.

78 Kharsany ABM, Hoosen AA, Sturm AW. Granuloma inguinale-a review. $S$ Afr J Epidemiol Infect 2001;16:40-9.

79 Wilkinson D, Connolly A, Harrison A, et al. Sexually transmitted disease syndromes in rural South Africa: results from health facility surveillance. Sex Transm Dis 1998:25:20-3.

80 Funani I, Sonko R, Marumo E, et al. STls: routine monitoring and clinical sentinel surveillance of sexually transmitted infections. In: ljumba P, Day C, Ntuli A, eds. South African Health Review 2003. Health Systems Trust, 2004.

\section{CALL FOR PAPERS}

\section{Special issue on sex workers}

n October 2006 STI will produce a special edition of the journal addressing health issues of sex workers and their partners. Global changes in migration, health, employment, and public policy are having a major impact on the sex industry and this themed issue provides an opportunity to reflect on this experience, and on how we can work effectively to improve the health and wellbeing of sex workers.

Helen Ward and Sevgi Aral will act as editors for this special edition, working closely with a team of expert reviewers from around the world.

We would like to receive articles reporting on research and interventions working with a range of people in and around the sex industry, including women, men and transgender sex workers, clients, other partners, and managers. We encourage analytic studies, including those assessing change, and welcome contributions based on novel interventions including community mobilisation. We hope to draw together a powerful collection of articles that provide evidence of effective interventions to improve health.

Authors wishing to submit original or review articles for this edition should submit their manuscripts electronically via Bench $>$ Press at www.stijournal.com. Please select the "sex work edition" section when submitting your manuscript. All manuscripts will be peer reviewed. The following article types will be considered:

- original research articles (up to 2500 words, maximum 30 references, and 3-4 tables or figures)

- short reports (up to 750 words, up to 10 references, and one figure or table)

- review article (up to 3000 words and 60 references).

Deadline for the receipt of manuscripts is 28 February 2006. Articles received after this date will not be considered.

H Ward

Editor, STI, BMJ Journals, BMA House, Tavistock Square, London WC1H 9JR, UK; h.ward@imperial.ac.uk

S Aral

Centers for Disease Control and Prevention (CDC), 1600 Clifton Road, Atlanta 30333, USA 